\title{
Behaviour of Concrete Filled Rectangular Steel Tube Column
}

\author{
Anil Kumar Patidar \\ P. G. Student, Department of Civil Engineering, School of Mechanical and Building Sciences (SMBS) \\ VIT University - Chennai Campus, Chennai - 600127, Tamil Nadu
}

\begin{abstract}
The Concrete Filled Steel Tube (CFST) member has many advantages compared with the conventional concrete structural member made of steel reinforcement. CFSTs are frequently used for columns, caissons and for piers, deep foundations because of their large compressive stiffness. The FEA modeling using ANSYS software is adopted to investigate the load versus lateral deflection behavior of the composite sections. The effects of steel tube thickness and strength of in-filled concrete tubes are examined. The size of the column is $140 \times 160 \times 1500 \mathrm{~mm}$ and the grades of concrete infill are M20, M30 and M40. The thickness of the tube is taken as $2 \mathrm{~mm}, 3 \mathrm{~mm}, 4 \mathrm{~mm}, 5 \mathrm{~mm}$ and $6 \mathrm{~mm}$ and, the D/t ratio varies from 26.67 to 80.00 .
\end{abstract}

Keywords: ANSYS, Axial strength, Concrete infill, Lateral deflection, Steel tube,

\section{INTRODUCTION}

Since past few decades, composite steel-concrete construction of column and girder is being used in the construction industry. These composite sections have the rigidity and formability of reinforced concrete with the strength and speed of construction associated with structure, thereby making them economical. The steel and the concrete element in a composite member complement each other ideally. Composite members consisting of rectangular steel tubes filled with concrete are extensively used in structures involving very large applied moments, particularly in zones of high seismic risk. Concrete Filled Tubes (CFTs) have been used as girder, beam and columns in frame structures. A steel hollow section in-filled with concrete has higher strength and larger stiffness than the conventional structural steel section and reinforced concrete. Composite column are structural members, which are mainly subjected to forces and end moments. The steel tube serves as a formwork for casting the concrete, which reduces the construction cost. No other reinforcement is needed since the tube itself act as a longitudinal and lateral reinforcements for the concrete core. The continuous provided to the concrete core by the steel tube enhances the core's strength and ductility. The concrete core delays bending and buckling of the steel tube, while steel tube prevents the concrete from spalling. Also concrete filled tube (CFT) columns are suitable for tall buildings in high seismic regions since concrete delays the local buckling of steel hollow sections and increases the ductility of the section significantly. While there is a large number of studies on the behaviour of CFT columns and beam-columns; there is relatively little research reported on the flexural behaviour of concrete-filled hollow structural steel column. The structural behavior of a CFT is governed by the member strength, reflecting the fact that the load resistance is dependent not only on the material properties but also on the geometric properties of the entire member. Tests on CFTs by Bridge showed that the concrete core only provides approximately $7.5 \%$ of the capacity in members under pure bending. Lu and Kennedy studied strength on twelve beams of concrete-filled Steel Square and Rectangular Hollow Sections for examining the effects of different depth to width ratios and different values of shear span to depth. The tests showed that the ultimate flexural strengths of the composite beams are increased by about $10 \%-30 \%$ over that of bare steel sections, depending on the relative proportions of steel and concrete. Although composite columns of concrete and steel were rarely used from the end of World War II until the early 1970s (Viest et al. 1997, 1.13), research had started a long time before, at the beginning of the 20th century. Combining of these materials had a number of motivations; steel columns were often encased in concrete to protect them from fire, while concrete columns were combined with structural steel as reinforcement.

The model is created for different width-to-wall thickness ratios (from 26.67 to 80.00) and different concrete cube strengths $(27.8,42,51 \mathrm{MPa})$. It is found that in general, concrete filling of the steel tube enhances strength, ductility and energy absorption especially for thinner sections. Han proposed a mechanics model that can predict the behaviour of concrete-filled hollow structural sections. In this paper, CFTs with three different wall thicknesses (Table 1) are selected $(\mathrm{D} / \mathrm{t}=26.67-80.00)$. Three different grades of concrete in-fills are considered. An effort is made to find the relative contributions of the steel tube and the confined concrete core to the moment capacity and deformation of CFTs under flexure. 


\section{MATERIAL}

\section{A. Concrete}

The characteristic strengths of concrete used in this paper 20, 30 and $40 \mathrm{MPa}$. Locally available Portland Cement (PPC), crushed jelly $(12 \mathrm{~mm})$ and river sand are used in the present investigation. Mix designs of these three grades of concrete are made based on the guidelines of IS 10262-1978.

\section{B. Steel tubes}

Mild steel tubes, cold-formed with yield strength of $250 \mathrm{MPa}$ and $1500 \mathrm{~mm}$ long are used in the present investigation. These tubes are seam welded and the edges of the tubes are finished.

\section{Composite column}

A composite column is a compression member, comprising either a concrete encased hot-rolled steel section or a concrete filled tubular section of hot-rolled steel and is generally used as a load-bearing member in a composite framed structure. Table 1 shows the details of the sections.

Table 1Details of sections

\begin{tabular}{|l|l|l|}
\hline $\begin{array}{l}\text { Dimension of CFST } \\
\mathrm{D} \times \mathrm{B}(\mathrm{mm})\end{array}$ & Thickness $(\mathrm{mm})$ & $\mathrm{D} / \mathrm{t}$ ratio \\
\hline $160 \times 140$ & 2 & 80.00 \\
\hline $160 \times 140$ & 3 & 53.33 \\
\hline $160 \times 140$ & 4 & 40.00 \\
\hline $160 \times 140$ & 5 & 32.00 \\
\hline $160 \times 140$ & 6 & 26.67 \\
\hline
\end{tabular}

\section{MODEL DEVELOPMENT}

A. Element Type

i. Shell 63 element has been used in the linear buckling analysis, which is a 4-noded 3-dimensional quadrilateral elastic shell element. It has both bending and membrane capabilities. Both in-plane and normal loads are permitted. The element has six degrees of freedom at each node: 3translations and 3 rotations. Stress stiffening and large deflection capabilities are included. A consistent tangent stiffness matrix option is available for use in large deflection analyses.

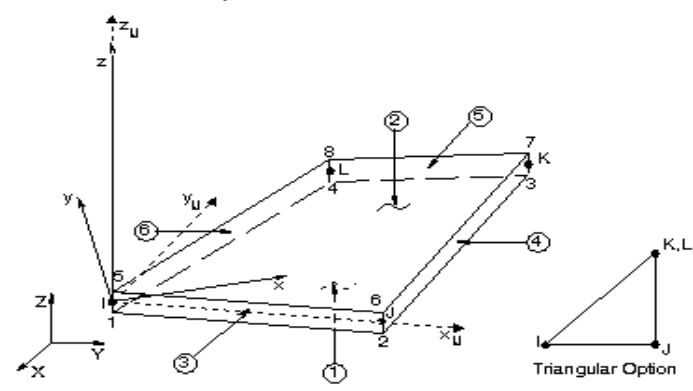

Figure 1: Element Characteristics of Shell 63

ii. Shell 43 element has been used in the non-linear post-buckling analysis. This element is well suited to model linear, warped, moderately-thick shell structures. The element has six degrees of freedom at each node: translations in the nodal $\mathrm{x}, \mathrm{y}$, and $\mathrm{z}$ directions and rotations about the nodal $\mathrm{x}, \mathrm{y}$, and $\mathrm{z}$ axes. The deformation shapes are linear in both in-plane directions. For the out-of-plane motion, it uses a mixed interpolation of tensorial components.

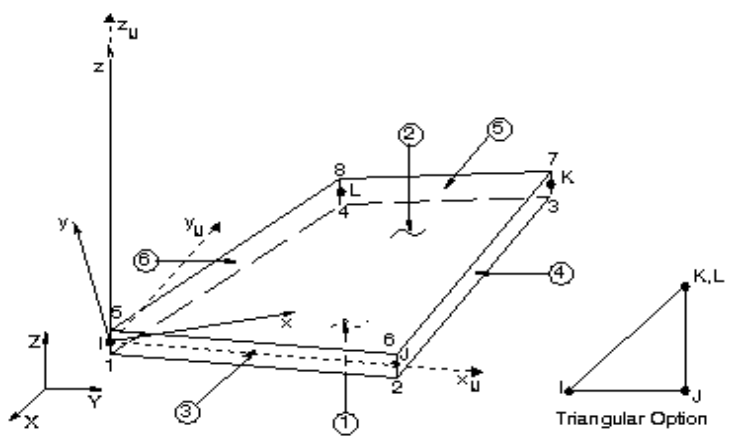

Figure 2: Element characteristics of shell 43 
iii. Solid 65 element type has been used to model the in-fill both plain cement concrete and steel fiber reinforced concrete varying the material property and its non linearity for non-linear analysis. It is used for 3-D modelling of slid with or without reinforcing bars. The solid element has eight nodes with three degrees of freedom at each node - translations in the nodal $\mathrm{x}, \mathrm{y}$, and $\mathrm{z}$ directions. The element is capable of plastic deformation, cracking in three orthogonal directions, and crushing. The geometry and node locations for this element type are shown in Figure 3.

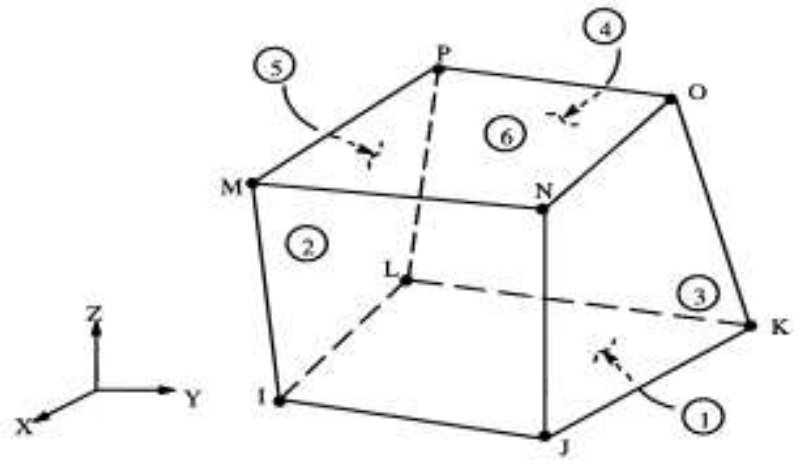

Figure 3: Solid65 - 3-D reinforced concrete solid

A Link8 element was used to model the steel reinforcement. Two nodes are required for this element. Each node has three degrees of freedom, - translations in the nodal $\mathrm{x}, \mathrm{y}$, and $\mathrm{z}$ directions. The element is also capable of plastic deformation.

iv. Solid 45element type has been used to model the end plates, which are used to distribute the load over the column section. This element is defined by eight-node with three degrees of freedom at each node translations in the nodal $\mathrm{x}, \mathrm{y}$, and $\mathrm{z}$ directions. The geometry and node locations for this element type are shown in Figure 4.

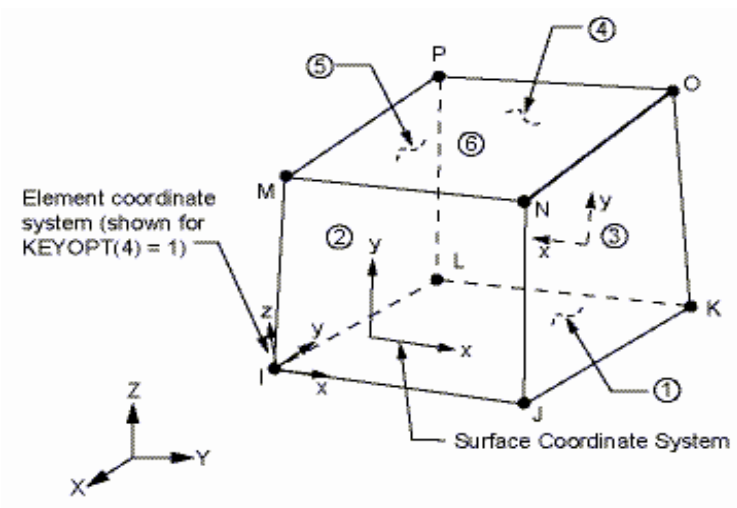

Figure 4: Solid45 - 3-D solid

\section{B. Boundary Conditions}

The end boundary conditions for all the finite element models were chosen to simulate the actual experimental set up. The ball and bolted end conditions are considered as pinned end conditions.

The pin ended boundary condition has been modeled by restraining all the translational degrees of freedom and rotational degree of freedom of the nodes at both ends, except the translational degree of freedom in the axial direction at the top end of the column. Since the load is applied from the top of the column the translational degree of freedom has been released. The nodes other than the two ends are free to translate and rotate in $\mathrm{x}, \mathrm{y}$ and $\mathrm{z}$ directions.

\section{Model overview:}

The structural analysis program ANSYS is used to construct the FE model for steel tube and CFST. Typical cross-sections of composite columns with and without concrete infilled steel sections are illustrated in Fig. 5 and Fig. 6. The meshing of CFST is modeled in medium size as shown in Fig 7. 


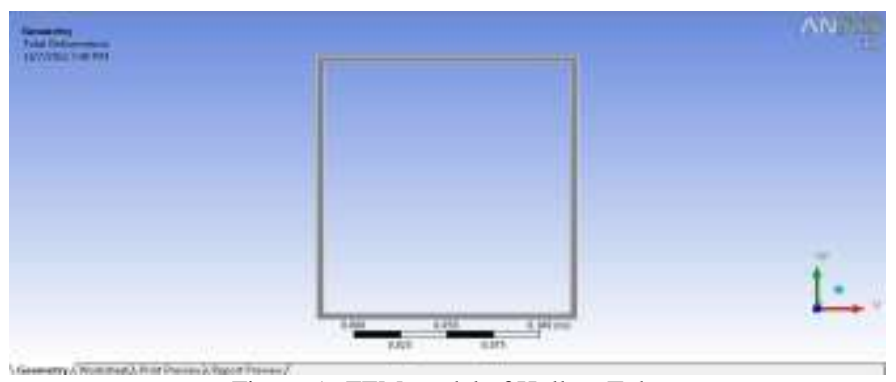

Figure 5: FEM model of Hollow Tube

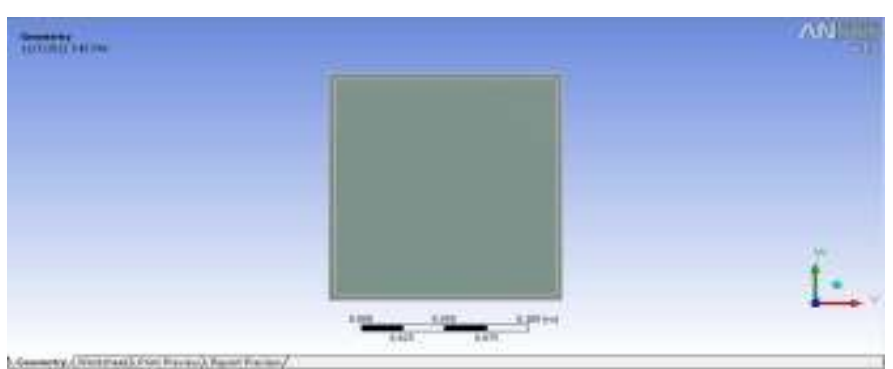

Figure 6: FEM model of CFST

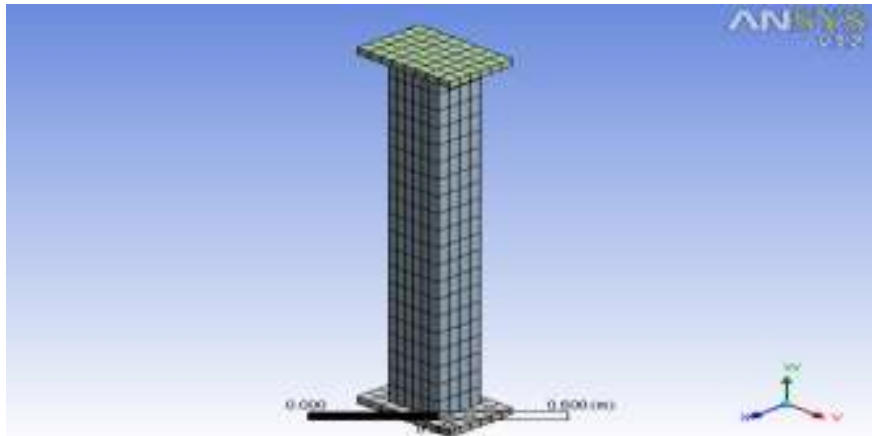

Figure 7: Finite elemnt meshing model for CFST.

\section{ANALYTICAL INVESTIGATION}

The non-linear finite element analysis program ANSYS12 has been used to predict the ultimate loads, and failure modes of hollow and in-filled light gauge steel section under hinged end conditions. The numerical simulation consists of two stages. Eigen value elastic buckling analysis is performed on a perfect geometry to establish probable buckling modes of a column.

In the second stage, a non-linear analysis is performed incorporating geometric non-linearity of the infills to obtain the ultimate load and the failure modes of the column. In the finite element model, the crosssectional dimensions and the material properties from the tests are modeled. The model is based on the centreline dimensions of the cross-sections.

Buckling loads are critical loads where certain types of structures become unstable. Each load has an associated buckled mode shape. This is the shape that the structure assumes in a buckled condition. There are two primary means to perform a buckling analysis.

\section{A. Eigenvalue analysis}

Eigenvalue analysis predicts the theoretical buckling strength of a structure which is idealized as elastic. For a basic structural configuration, structural eigenvalues are computed from constraints and loading conditions. Buckling loads are then derived, each associated with a buckled mode shape which represents the shape a structure assumes under buckling. In a real structure, imperfections and nonlinear behavior keep the system from achieving this theoretical buckling strength, leading Eigenvalue analysis to over-predict buckling load.

\section{B. Nonlinear buckling analysis}

Nonlinear buckling analysis provides greater accuracy than elastic formulation. Applied loading incrementally increases until a small change in load level causes a large change in displacement. This condition indicates that a structure has become unstable. Nonlinear buckling analysis is a static method which accounts for 
material andgeometric nonlinearities (P- $\Delta$ and $\mathrm{P}-\delta$ ), load perturbations, geometric imperfections, and gaps. Either a small destabilizing load or an initial imperfection is necessary to initiate the solution of a desired buckling mode.

Nonlinear buckling can be performed on the original structure without imperfection, or by automatically adding an imperfection based upon a scaled deformed shape which could be from a linear buckling model.

A structure may also experience some material nonlinearity during a buckling event (yielding for example) and/or some boundary nonlinearity (lift-off supports, perhaps). Generally it is recommended that modelling of nonlinear effects is done progressively in order to evaluate the results of each additional modelling at each stage. This helps in developing an understanding of the structural behaviour and helps to identify the cause of any potential failed analyses.

\section{RESULT AND DISCUSSION}

The deflected profile of the hollow tube is shown in Figure 8 and the Figure 9 shows the deflected profile of the typical CFST.

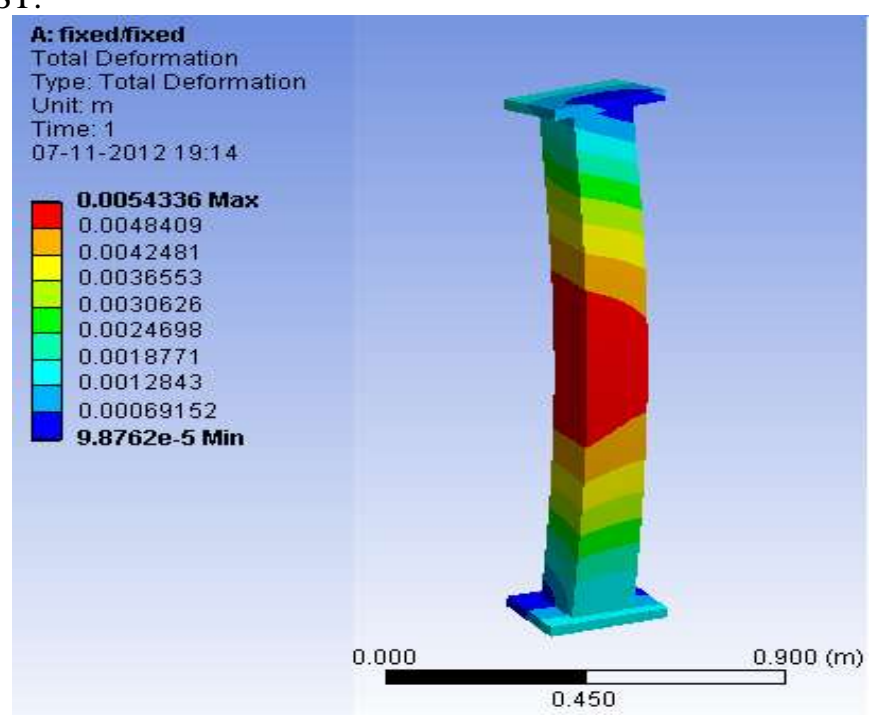

Figure 8: Deflected Profile of Hollow Tube

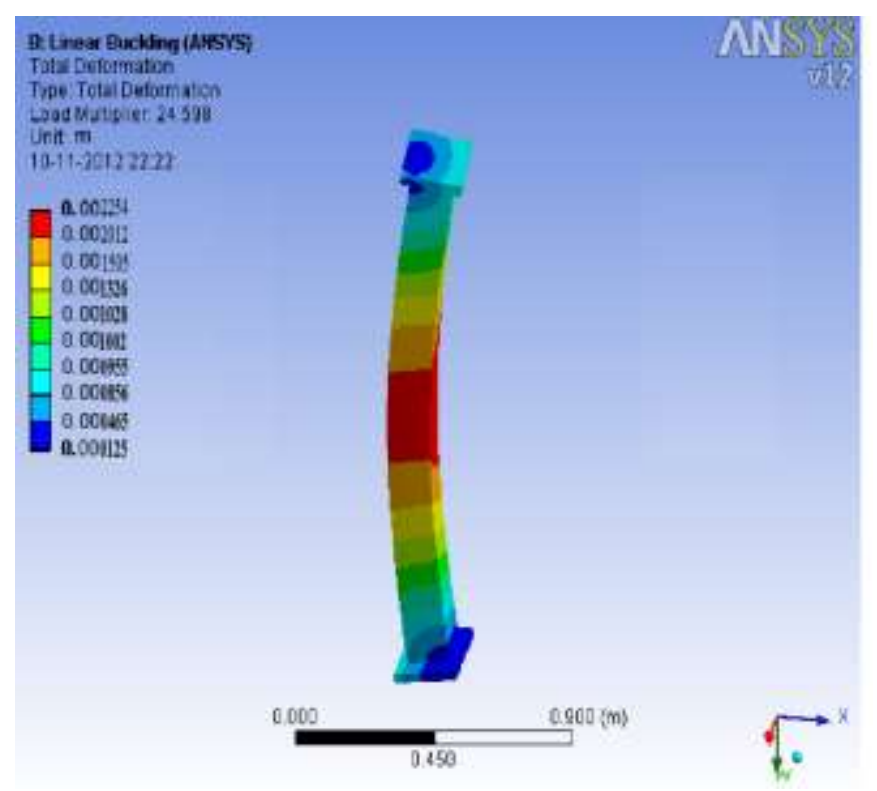

Figure 9: Deflected Profile of Typical CFST

The deflection is maximum at the mid heights of the columns for concentrically loaded columns. The $6 \mathrm{~mm}$ thick column shows good response against deformation because of $\mathrm{D} / \mathrm{t}$ ratio.

The load versus lateral deflection behavior of hollow and CFST for different wall thicknesses are studied and the results are plotted in the Figures from 10 (a) to (e). 


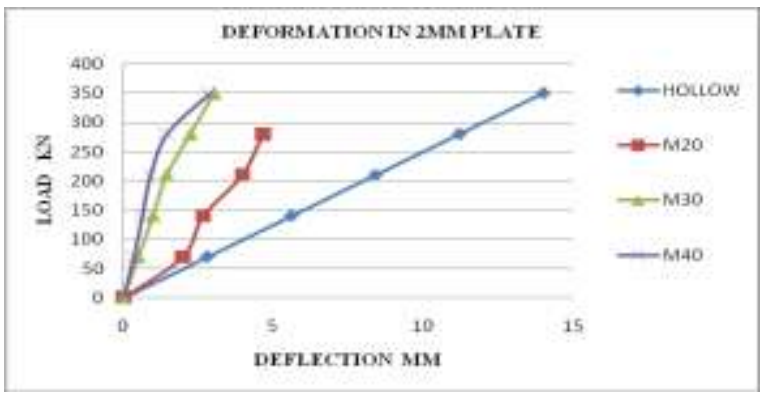

(a)

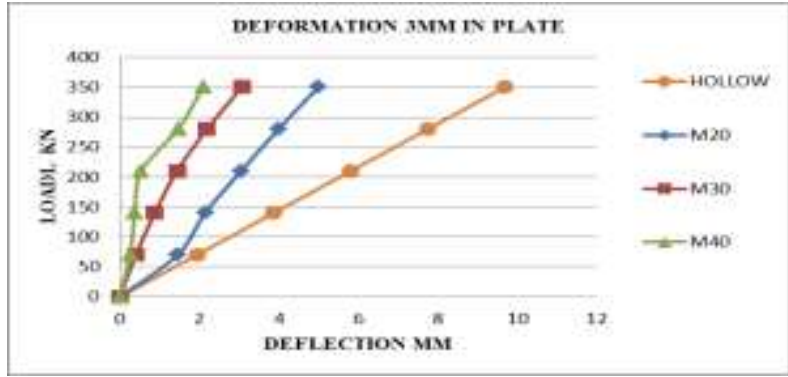

(b)

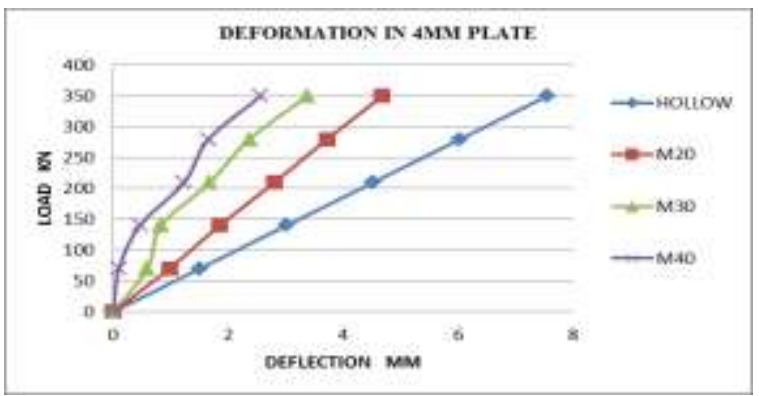

(c)

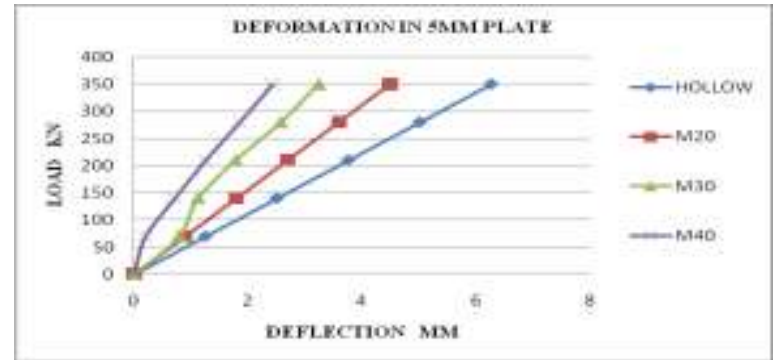

(d)

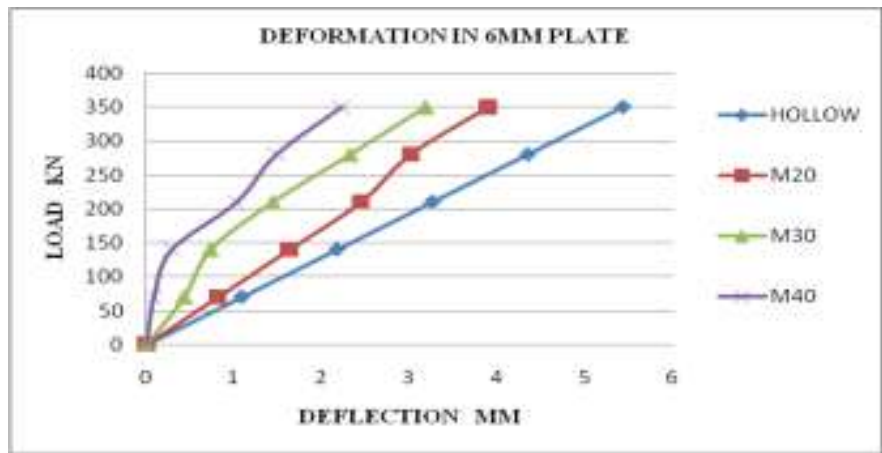

(e)

Figure 10 Load versus Deflection Behaviours of columns 


\section{CONCLUSION}

The FEM model of hollow and CFST columns are developed using ANSYS software and the load versus behavior of columns is studied. The following conclusions are derived based on the obtained results.

(1) The finite element proposed model shows the resistance to deformation when concrete is used as infill material and deformation decreases when an increase in the grade of concrete.

(2) The hollow steel tube column however deform to a greater extent as compared with the column having the in fill material.

(3) The $6 \mathrm{~mm}$ thick column shows good response against deformation because of $\mathrm{D} / \mathrm{t}$ ratio.

\section{Reference}

[1] Gho Wie-Min, Liu Dalin. Flexural behavior of high-strength rectangular concrete-filled steel hollow sections. Journal of Constructional Steel Research 2004;60:1681-96.

[2] Han Lin-Hai. Flexural behaviour of concrete-filled steel tubes. Journal of Constructional Steel Research 2004;60:313 37

[3] Bridge RQ. Concrete filled steel tubular columns. Report no. R283. Sydney (Australia): School of Civil Engineering, University of Sydney; 1976.

[4] Lu YQ, Kennedy DJL. The flexural behavior of concrete-filled hollow structural sections. Canadian Journal of Civil Engineering 1994;21(1):11-130.

[5] ANSYS - Finite element structural analysis program using workbench version 12

[6] IS 10262-1982. Indian standard recommended guidelines for concrete mix design. Bureau of Indian Standards, New Delhi, India

[7] Baltay P, Gjelsvik A. Coefficient of friction for steel on concrete at high normal stress. J Mater Civil Eng ASCE 1990;2(1):46-9

[8] ANSYS user's manuals.

[9] Hui-shen Shen and Williams F.W.(1993), 'Post buckling Analysis of stiffened Laminated Box Columns', Journal of Engineering Mechanics, Vol. 119, no. 1, pp 825-838.

[10] Lignola G.P.A. Prota A, Manfredi G and Cosenza E (2007), 'Experiment performance of RC Hollow Columns Confined with CFRP' 